\title{
Longitudinal melanonychia on multiple nails induced by hydroxyurea
}

\author{
Anh Ly Nguyen, ${ }^{1}$ John E Körver, ${ }^{2}$ Chantal C W Theunissen ${ }^{3}$
}

${ }^{1}$ Department of Dermatology, Leids Universitair Medisch

Centrum, Leiden,

The Netherlands

2Department of Dermatology, Amphia Ziekenhuis, Breda, The Netherlands

${ }^{3}$ Department of Dermatology, Albert Schweitzer Ziekenhuis, Dordrecht, The Netherlands

\section{Correspondence to Dr John E Körver, jkorver@amphia.nl}

Accepted 3 February 2017
CrossMark

To cite: Nguyen $A \mathrm{~L}$, Körver JE, Theunissen CCW. BMJ Case Rep Published online: [please include Day Month Year] doi:10.1136/ bcr-2016-218644

\section{DESCRIPTION}

A Caucasian woman aged 67 years presented to our outpatient clinic with an 18 months history of asymptomatic continuously progressing longitudinal brown bands on her toenails. There was no history of trauma or friction to her toenails. She was ineffectively treated with oral terbinafine for 3 months due to suspected onychomycosis. Since 3 years, she received treatment for polycythaemia vera with hydroxyurea in varying doses ranging from 500 to $1500 \mathrm{mg}$ daily. Her polycythaemia vera was adequately regulated. She experienced no other side effects. Her medical history was otherwise unremarkable. Family history was negative for longitudinal melanonychia and melanoma.

Physical examination showed multiple longitudinal brown-pigmented bands on eight toenails with subungual hyperkeratosis. Pseudo-Hutchinson's sign was present as the pigmentations extended proximally beneath the translucent cuticles, but the cuticles and nail folds were not affected (figures 1 and $2 \mathrm{~A}$ ). Her fingernails were normal. No other mucocutaneous pigmentations were seen.

The differential diagnosis of longitudinal melanonychia affecting multiple nails consists of an iatrogenic cause like drug-induced hyperpigmentation, physiological, repetitive trauma, subungual haematoma, onychomycosis, pseudomonas infection or underlying systemic disease. Subungual melanocytic naevus or melanoma were unlikely as
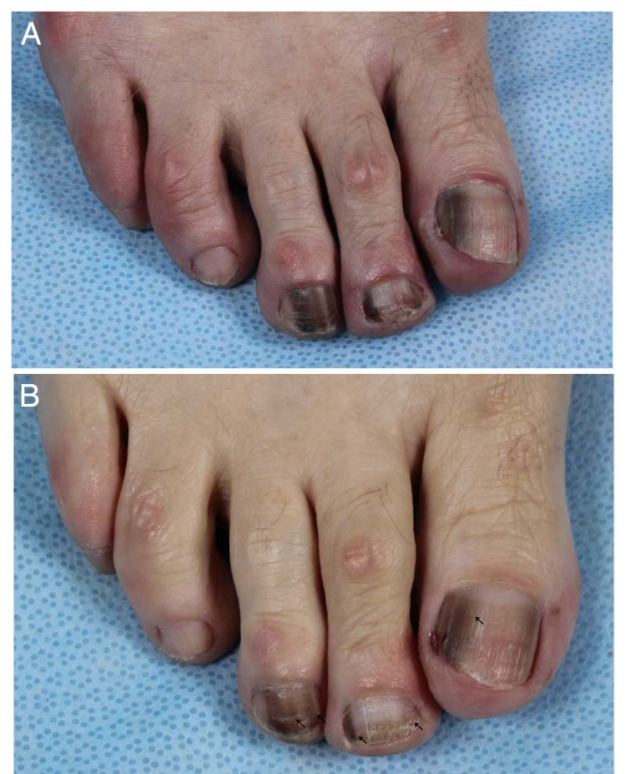

Figure 1 Multiple longitudinal brown bands on the toenails of digiti I-III of the right foot during treatment with hydroxyurea $(A)$ and 6 weeks after discontinuation of hydroxyurea (B).
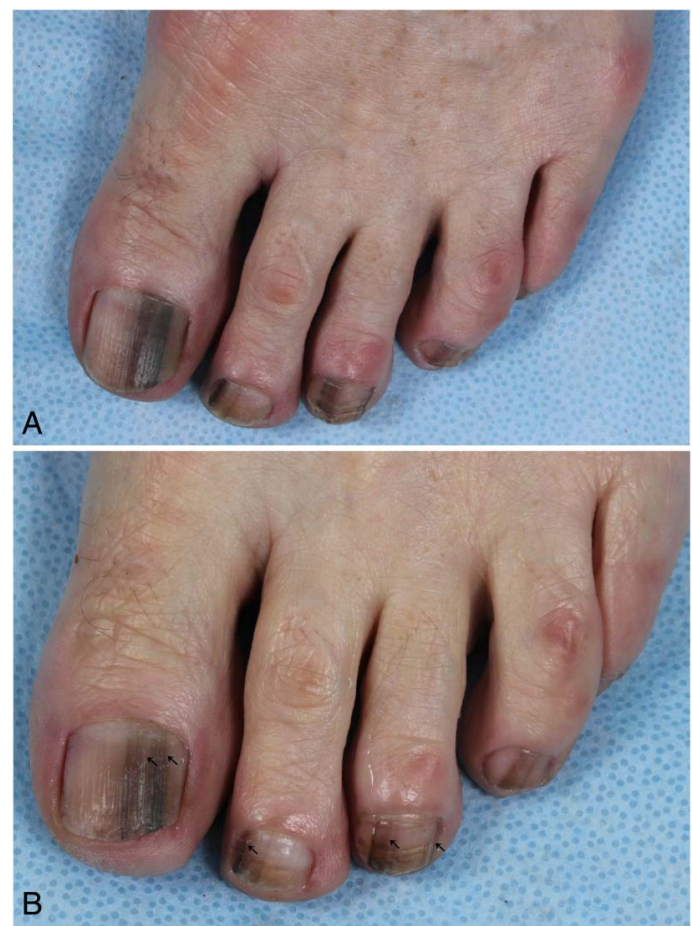

Figure 2 Multiple longitudinal brown bands on all the toenails of the left foot during treatment with hydroxyurea (A) and 6 weeks after discontinuation of hydroxyurea (B).

multiple nail units were affected. Subungual melanoma was also unlikely due to the absence of micro-Hutchinson's sign and Hutchinson's sign. Our patient was diagnosed with a drug-induced melanonychia caused by hydroxyurea.

She requested temporary discontinuation of the drug as she experienced cosmetic inconvenience due to the discoloured toenails. Already 6 weeks after discontinuation, outgrowth of the brown bands was visible with significant lightened brown colouring of the pigmentations (figures 1 and $2 \mathrm{~B}$ ). The patient was unable to suspend the drug permanently.

Melanonychia are an uncommon side effect of hydroxyurea. This is a cytostatic drug used for management of myeloproliferative disorders. Melanonychia develops in about $4.3 \%$ of the patients receiving hydroxyurea therapy. ${ }^{1}$ The onset of the melanonychia varies from 4 weeks to 5 years after initiation of the hydroxyurea. ${ }^{2} 3$ This case demonstrates that an iatrogenic (drug-induced) cause should be considered in the case of longitudinal melanonychia affecting multiple nails. Malignant melanoma should be considered and ruled out in the case of a single affected nail. Hutchinson's sign and micro-Hutchinson's sign are important clinical clues 


\section{Learning points}

- In the case of longitudinal melanonychia of multiple nail units, an iatrogenic cause should be considered. The most important cause is the use of (cytostatic) drugs.

- Melanonychia are a rare side effect that occurs in about $4.3 \%$ of patients receiving hydroxyurea therapy.

- Longitudinal melanonychia can extend beneath the translucent cuticle without involving the cuticle or nail fold, which is considered a pseudo-Hutchinson's sign.

- Micro-Hutchinson's sign is present when a hyperpigmentation in the cuticle is only visible on dermoscopy. Hutchinson's sign is a macroscopic nail pigmentation extending into the cuticle and nail fold. Both are important clinical clues for subungual melanoma.

to subungual melanoma. ${ }^{4}$ Hutchinson's sign is characterised by a macroscopic hyperpigmentation of the cuticle and adjacent nail fold. ${ }^{4}$ Micro-Hutchinson's sign is present when a hyperpigmentation is limited to the cuticle, but is only visible on dermoscopy and not with the naked eye. ${ }^{5}$ Longitudinal melanonychia can be associated with a hyperpigmentation that extends beneath the translucent cuticle, without involving the cuticle and/or nail fold. This hyperpigmentation simulates micro-Hutchinson's sign, but is in fact a pseudo-Hutchinson's sign of the illusory type, that is visible due to transparency of the cuticle. ${ }^{4}$ Antimycotic treatment is not useful. After discontinuation of the inducing drug, the melanonychia will disappear as the nail grows.

Contributors ALN, CCWT and JEK all made substantial contributions to conducting, reporting, conception, design, analysis and interpretation of the case report. ALN, CCWT and JEK also drafted the article and revised it critically for important intellectual contact and gave final approval of the submitted version.

Competing interests None declared.

Patient consent Obtained.

Provenance and peer review Not commissioned; externally peer reviewed.

\section{REFERENCES}

1 Aste N, Fumo G, Contu F, et al. Nail pigmentation caused by hydroxyurea: report of 9 cases. J Am Acad Dermatol 2002:47:146-7.

2 Las Heras G, Juncà Piera J. Nail changes after chemotherapy. Haematologica 1998;83:748.

3 Delmas-Marsalet B, Beaulieu P, Teillet-Thiebaud F, et al. Longitudinal melanonychia induced by hydroxyurea: four case reports and review of literature. Nouv $\mathrm{Rev} \mathrm{Fr}$ Hematol 1995;37:205-10.

4 Baran R, Kechijian P. Hutchinson's sign: a reappraisal. J Am Acad Dermatol 1996;34:87-90.

5 Koga H, Saida T, Uhara H. Key point in dermoscopic differentiation between nail apparatus melanoma and benign longitudinal melanonychia. J Dermatol 2011;38:25-34.

Copyright 2017 BMJ Publishing Group. All rights reserved. For permission to reuse any of this content visit http://group.bmj.com/group/rights-licensing/permissions.

BMJ Case Report Fellows may re-use this article for personal use and teaching without any further permission.

Become a Fellow of BMJ Case Reports today and you can:

- Submit as many cases as you like

- Enjoy fast sympathetic peer review and rapid publication of accepted articles

- Access all the published articles

- Re-use any of the published material for personal use and teaching without further permission

For information on Institutional Fellowships contact consortiasales@bmjgroup.com

Visit casereports.bmj.com for more articles like this and to become a Fellow 